\title{
Crown bulk density and fuel moisture dynamics in Pinus pinaster stands are neither modified by thinning nor captured by the Forest Fire Weather Index
}

\author{
Marc Soler Martin ${ }^{1}$. José Antonio Bonet ${ }^{1,2}$ • Juan Martínez De Aragón ${ }^{2} \cdot$ Jordi Voltas $^{1}$. \\ Lluís Coll ${ }^{2,3,4}$ • Víctor Resco De Dios ${ }^{1}$ (B)
}

Received: 17 March 2017 / Accepted: 9 June 2017 / Published online: 28 June 2017

(C) INRA and Springer-Verlag France SAS 2017

\begin{abstract}
- Key message No temporal change was recorded during summer in fuel availability in Pinus pinaster stands, contrary to predictions from the Forest Fire Weather Index. Also, thinning had no mid-term effect on fuel moisture or canopy structure.

- Context Forest fires are a major problem in Mediterranean countries. Management actions, such as fuel reductions, are one of the main tools to diminish fire risk, but the midterm
\end{abstract}

\section{Handling Editor: Eric Rigolot}

Contribution of co-authors

Marc Soler Martin: designing the experiment, collecting data, running the data analyses, and writing the paper.

Juan Martínez de Aragón: designing the experiment and collecting data. José Antonio Bonet: designing the experiment, collecting data, and writing the paper.

Jordi Voltas: running the data analyses and writing the paper.

Lluís Coll: writing the paper.

Víctor Resco de Dios: designing the experiment, running the data analyses, writing the paper, and supervising the work.

Electronic supplementary material The online version of this article (doi:10.1007/s13595-017-0650-1) contains supplementary material, which is available to authorized users.

Víctor Resco De Dios

v.rescodedios@gmail.com

Marc Soler Martin

markus_07_04@hotmail.com

José Antonio Bonet

jantonio.bonet@exchange.ctfc.es

Juan Martínez De Aragón

mtzda@ctfc.es

Jordi Voltas

jvoltas@pvcf.udl.cat efficacy of such tools remains largely untested with empirical data.

- Aims Here, we test for midterm effects of thinning on fuel moisture and crown bulk density in P. pinaster stands and whether temporal variations in fuel moisture correlated with predictions from the Fire Weather Index, a commonly used index on fire risk, and its components.

- Methods We compared fuel moisture over a fire season and crown bulk density in nine pairs of thinned/unthinned plots 7 years after treatments were applied.

- Results We observed that fuel moisture remained stable during a fire season, as a likely result of drought-induced physiological adjustments, including stomatal regulation and others, which allow leaves to maintain a large humidity even during drought, and that thinning had no midterm effect on fuel moisture or crown bulk density. Moreover, the Fire Weather Index and its components displayed different temporal dynamics than those observed in fuel moisture.

- Conclusion These results are important as they indicate that thinning may only have a limited, short-term impact towards diminishing the potential for crown fire spread in these stands and that current indices to evaluate fire risk may require a re-evaluation.

Lluís Coll

lluis.coll@ctfc.es

1 Department of Crop and Forest Sciences-AGROTECNIO Center, Universitat de Lleida, 25198 Lleida, Spain

2 Centre Tecnològic Forestal de Catalunya (CTFC-CEMFOR), 25280 Solsona, Spain

3 CREAF, 08193 Cerdanyola del Vallès, Spain

4 Department of Agriculture and Forest Engineering (EAGROF), University of Lleida, 25198 Lleida, Spain 
Keywords Crown bulk density $\cdot$ Crown fire $\cdot$ Fuel moisture Forest management · Mediterranean forests · Fire risk · Seasonal changes

\section{Introduction}

Forest fires are a major environmental problem in many areas worldwide, including Southern Europe. The average number of forest fires in EU Mediterranean countries is of 50,000 year $^{-1}$, which annually burn around 0.5 Mha (SanMiguel and Camia 2009; Moreno et al. 2013). Forest fires depend upon the concurrence of four factors, with markedly different temporal dynamics (Bradstock 2010): (i) fuel load, which results from plant growth and changes at inter-annual or decadal scales; (ii) fuel availability, which depends mostly upon its moisture and changes during and across seasons; (iii) fire weather, which provides the conditions necessary for fire spread and varies within days; and (iv) ignition sources, which occur at very short and irregular intervals and often involve human action (arson or negligence) or lightning.

Within the different forest fire types, crown fires are the most problematic from an operational point of view because they burn at very high intensity and often beyond extinction capacity (Rothermel 1983; Alexander and Cruz 2011; Alvarez et al. 2012). In turn, the likelihood of a crown fire depends upon complex interactions between surface and understory fuel load and characteristics, height of the crown base, and crown bulk density (CBD), which jointly determine the fuel load, and by the moisture of thin particles (<3-mm width), which determines fuel availability (van Wagner 1977; Alexander 1988; van Wagner 1993). Once a crown fire has initiated, CBD and fuel moisture (FM) will be amongst the most critical parameters determining its spread (van Wagner 1977).

Given the importance of fuel load for determining fire spread probabilities, it has been proposed that fuel reduction treatments could diminish fire spread (Agee and Skinner 2005; Piñol et al. 2007) and fire severity, amongst other benefits (McIver et al. 2013). This is because fuel reduction treatments diminish fuel continuity. The efficacy of these fuel reduction treatments is currently discussed, given the large area needed and limited leverage, but a full review of this topic is beyond the scope of this study (Fernandes et al. 2013; Moritz et al. 2014; Boer et al. 2015; North et al. 2015).

It is trivial that CBD will diminish immediately after thinning. For how long will that effect be sustained is less clear. It is currently assumed that fuel reduction treatments in Mediterranean forests need to be performed, roughly, every 15-20 years, implying that this is the period of time that it should take for fuel loads to reach the same accumulation as before the thinning (Agee and Skinner 2005; Vélez 2010;
Stephens et al. 2012). Moreover, thinning decreases tree density and often leads to higher soil water availability, which should additionally lower the probability of a crown fire by increasing FM although, in some cases, less water may be available after increases in the exposure of bare soil enhance soil evaporation (Pretzsch 2009; Alfaro-Sánchez et al. 2016; Resco de Dios 2016). However, as for CBD, these effects may be limited in time if the canopy of the remaining trees quickly occupies the gap left by removed trees.

There is currently a paucity of data on the midterm effects of thinning on CBD and fuel moisture (FM). Some studies have examined the responses of shrubs (Potts et al. 2010; Kreye et al. 2014) and others the responses to prescribed fire (Fernandes 2009). However, the midterm effects of thinning to reduce crown fire potential in Mediterranean pine forests have only seldom been considered (Jiménez et al. 2016).

Fire risk is often considered to increase as the intensity of the summer water deficit, characteristic of Mediterranean environments, advances (Viegas et al. 1999; Bedia et al. 2015). This is reflected in the temporal variation of the different fire risk indices, amongst which the Fire Weather Index (FWI) is particularly widespread amongst regional and local meteorological agencies worldwide (van Wagner 1987). In short, FWI could be considered as a drought index, in that it relies on a basic water budget that predicts higher fire risk as water scarcity increases (note that FWI has also additional components to calculate fire risk, such as wind speed and other characteristics of fire weather, which will be explained in further detail in the methods). However, while FWI often increases as the summer advances, whether or not the probability of a crown fire actually increases depends not only upon meteorological factors, but also upon the physiological adjustments made by the trees and the shrubs, including stomatal regulation, osmotic and elastic adjustments, capacitance, and other mechanisms which allow leaves to maintain a large humidity even during drought.

One of the most widespread vegetation types in the Mediterranean is pine forests. Pine species are known to be isohydric, meaning that they display feedforward stomatal control of transpiration and leaf moisture remains relatively constant as drought advances (Klein 2014). Additionally, other adjustments such as osmotic and elastic adjustments and stem capacitance could also decouple leaf moisture from atmospheric drought for a period of time (although leaf moisture will eventually decline during an extreme drought). Amongst Mediterranean pine species, Pinus pinaster Ait. has the broadest ecological niche in Spain (from sea level to $1900 \mathrm{~m}$ and in different soil types) and is often subjected to prolonged summer drought (Gil et al. 1990). For an isohydric pine such as $P$. pinaster, we could therefore expect that, regardless of water availability, foliage moisture will remain stable throughout the fire season. Since shoot growth can be considered negligible during a fire season, crown fire risk should 
therefore remain stable throughout, indicating a constant fire risk during the growing season, except in those days where fire weather conditions (e.g., windy days) could enhance fire propagation.

Here, we test whether thinning has any legacy effects on FM and CBD 7 years after the treatment and whether seasonal dynamics of FM are appropriately captured by FWI and its components. Thinning leads to major structural changes in the canopy and in the understory, but here, we solely focused on FM and CBD as key canopy characteristics involved in crown fire propagation. We studied different stands of planted P. pinaster, as it is the dominant species within the $5 \mathrm{Mha}$ of planted forests that occur in Spain (Vadell et al. 2016), and about a third of all forest fires in Spain occur in P. pinaster stands (MAGRAMA 2012). We hypothesized that (i) thinned stands would show lower CBD than unthinned stands and (ii) also higher moisture and that (iii) foliage moisture would remain stable throughout the summer and the components of FWI relating to fuel availability would show limited predictive accuracy.

\section{Materials and methods}

We studied different stands of $P$. pinaster planted around 60 years ago. The experiment was conducted at the Natural Park of Poblet, in Tarragona, NE Spain (41 ${ }^{\circ} 21^{\prime} 6.4728^{\prime \prime}$ latitude and $1^{\circ} 2^{\prime} 5.7496^{\prime \prime}$ longitude). The climate is Mediterranean with a mean annual temperature of $13.2{ }^{\circ} \mathrm{C}$ and a mean annual precipitation of $600 \mathrm{~mm}$ (Bonet et al. 2012). The soil is loamy-sandy and well drained and originated from decomposed granite (Bonet et al. 2012). We used nine pairs of plots (18 plots in total) distributed across $2.3 \mathrm{~km}$ in distance. The plots were selected to represent a wide range of aspects, altitudes (from 609 to $903 \mathrm{~m}$ a.s.l.), and slopes (3$23 \%$; Table 1 ). The original planting density was $\sim 2500$ trees $\mathrm{ha}^{-1}$, but there were marked differences in density (688-2657 tree $\mathrm{ha}^{-1}$ ) and basal area $\left(31.5-61.1 \mathrm{~m}^{2} \mathrm{ha}^{-1}\right)$ across plots at the time of starting the experiment due to mortality and other factors. Each pair of plots contained a thinned and an unthinned $40 \mathrm{~m} \times 40 \mathrm{~m}$ plot, separated by $\sim 100 \mathrm{~m}$, which together represented a complete block for a randomized complete block experimental design with nine replicates. Different thinning intensities were conducted across plots, ranging from 8 to $57 \%$ of the basal area, during 2009 (Table 1). We conducted a systematic thinning (based on the position of the trees) manually in August 2009. The cut trees were removed from the plots with a winch and only the understory was masticated, with the residues being left in an area adjacent to the plot

Understory composition was heterogeneous and dependent on altitude. Quercus ilex L. occurred at highest altitudes, Cistus spp., Ilex aquifolium L., and Arbutus unedo L. 
appeared at intermediate altitudes, and in lower altitudes and near ravines occurred A. unedo L., Cistus spp., Ruscus aculeatus L., Juniperus communis L., I. aquifolium, Viburnum tinus L., Cytisus scoparius L., amongst others. Further details on site location and characteristics may be found elsewhere (Bonet et al. 2012).

\subsection{Crown bulk density sampling}

We estimated crown bulk density (CBD), from the approach of Keane et al. (2005):

$\mathrm{CBD}=\frac{2}{\mathrm{SLA}} \sum_{i=1}^{n} \frac{-\ln g \sin \theta \cos \theta}{z}$

where SLA, $g, \theta$, and $z$ are the specific leaf area $\left(\mathrm{m}^{2} \mathrm{~kg}^{-1}\right)$, gap fraction, zenith angle, and height (m), respectively. SLA was measured after determining the area in scanned leaves using ImageJ (Schneider et al. 2012) from a composite sample obtained from five trees across each plot and dividing the area by their dry weight. $g$ was measured from pictures taken at $\theta$ of $1^{\circ}, 30^{\circ}, 60^{\circ}, 89^{\circ}, 120^{\circ}, 150^{\circ}$, and $179^{\circ}$ zenith angles using the R package canopyphoto (Duursma 2013), with two replicates (two pictures at each zenith angle taken at opposite ends of each plot) at $2 \mathrm{~m}$ high.

However, we observed problems with this approach. In particular, no recommendation on either $n$ or $\theta$ was provided by Keane et al. (2005) and the right-hand side of the equation is not bounded in that it presents a summation, not an average. The value of CBD was therefore highly variable depending upon which combination of $\theta$ was taken (and on the $n$ chosen), and higher values occurred with more data points (data not shown). Therefore, for the benefit of parsimony, we chose to calculate a proxy for $\mathrm{CBD}$ (pCBD) instead as follows:

$p C B D=\frac{2}{\text { SLA }} \frac{-\ln g}{z}$

where $g$ is the average gap fraction measured at $90^{\circ}$ (that is, vertically up). It is well established that CBD correlates with photographic estimates of $g$ so, although Eq. 2 will not provide quantitative estimates of $\mathrm{CBD}$, it will provide values of pCBD that will be strongly correlated with actual CBD (Welles and Cohen 1996; Keane et al. 2005).

\subsection{Fuel moisture sampling}

We collected data from the different live and dead fuel types occurring at the site. Live fuel was collected from particles smaller than $3 \mathrm{~mm}$ in crown trees and also in shrubs. We collected five tins with $\sim 100 \mathrm{~g}$ of each fuel type per plot by using a composite of different trees (for crown fuel) and shrubs (for shrub fuel). Crown fuel was collected using a pole pruner from the upper half of the crown, in sunlit leaves. We attempted to sample also the herbaceous layer, but it was nonexistent in most plots.

In half the plots, we additionally collected dead fuel particles that were classified depending on their size as $1 \mathrm{~h}(<6 \mathrm{~mm})$ or $10 \mathrm{~h}(6-25.4 \mathrm{~mm})$, and we collected 1- and 10-h particles suspended and also on the surface. For each of these four fuel types, we also collected five tins of fuel per plot. Sampling effort was reduced, relative to that of live FM, such that only five pairs of plots (instead of the nine pairs used in live fuel assessments) remained because previous work has identified a chief influence of vapor pressure deficit (VPD) over dead fine FM, and VPD was expected to be high during the summer collection period such that dead fine FM would be uniformly low throughout the summer (Resco de Dios et al, 2015).

Measurements that would later be used in statistical analyses were conducted fortnightly between the second half of June and September (that is, during the fire season). Additionally, the study was initiated in late May, where biweekly sampling was conducted at one additional plot within the same area but different from the others, providing a "baseline" measurement (see Fig. A1; Online Appendix). These baseline measurements were conducted in weeks alternative to those in the rest of the plots, such that at least a sample was collected in every week. All samples were collected around noon (10:00-15:00 h).

After collection, samples were stored immediately in tins within a cooler, and sealed with Parafilm and transported to the laboratory. In the laboratory, samples were freshly weighed and then placed in an oven at $105^{\circ} \mathrm{C}$ for $48 \mathrm{~h}$. FM was calculated as the difference in fresh minus dry weight, relative to dry weight.

\subsection{Fire Weather Index}

FWI (van Wagner 1987) was calculated as in using the R package fireDanger (Bedia et al. 2015). In brief, the FWI contains five modules:

1. Fine Fuel Moisture Code indicates the availability of dead fine surface fuel from air temperature $\left(T_{\text {air }}\right)$, relative humidity $(\mathrm{RH})$, wind speed $(u)$, and rainfall $(P)$.

2. Duff Moisture Code indicates the moisture in the soil located under the organic material layer of moderate depth, dependent on $T_{\text {air }}, \mathrm{RH}$, and $P$.

3. Drought Code indicates the moisture content of the soil deeper layer and depends on $T_{\text {air }}$ and $P$.

4. Initial Spread Index describes the speed of propagation of fire, dependent on Fine Fuel Moisture Code (FFMC) and $u$.

5. Buildup Index indicates the amount of fuel available for combustion, dependent on no. 2 and no. 3. 
Meteorological data were obtained from the closest meteorological station available from the Catalan Service of Meteorology, which was about $5 \mathrm{~km}$ from the plots (Fig. 1). One of the approaches used by meteorological agencies to provide spatially explicit FWI estimates over regions is to use the value of a meteorological station to inform on FWI for the surrounding area, which often encompasses a few kilometers. We note that there could be some differences in microclimate between the meteorological station and the plots and also some differences across plots (which are spread over $2.3 \mathrm{~km}$ ), but microsite differences are not taken into account by current meteorological agencies (and those differences would not impact temporal patterns,
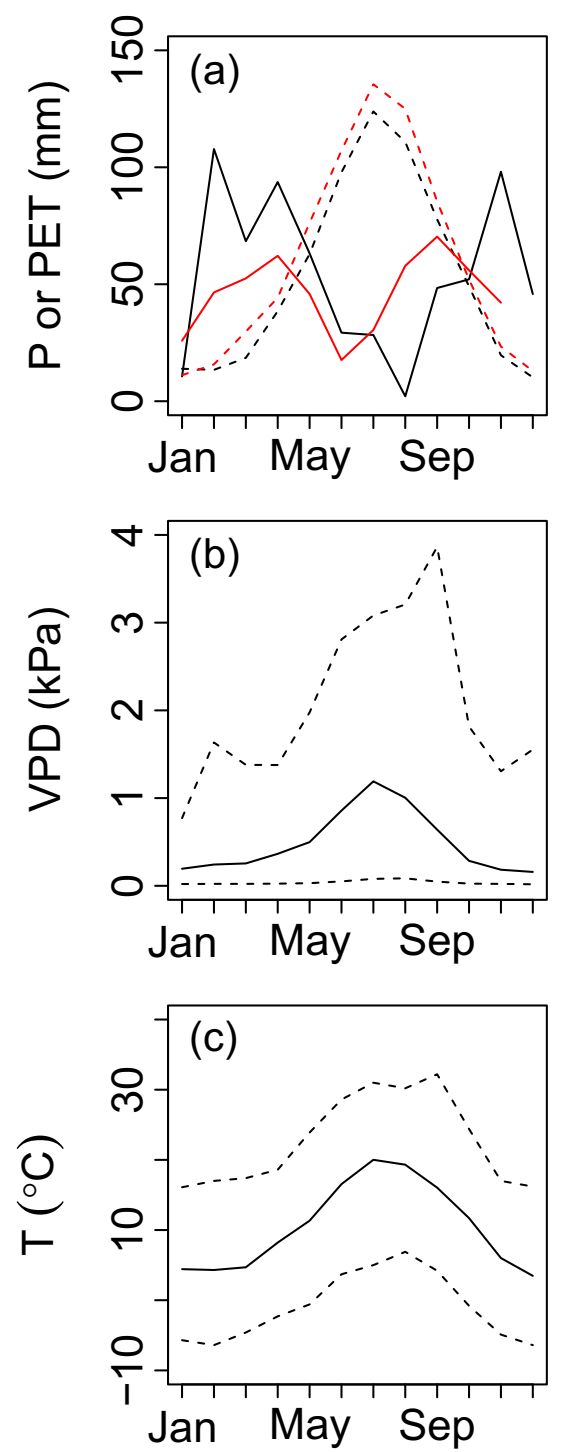

Fig. 1 Meteorological data from the nearest weather station. a Average (in red) and current year (in black) precipitation (continuous line) and Thornthwaite's potential evapotranspiration (dashed line). b, c Current year average (continuous line) and maximum and minimum (dashed lines) vapor pressure deficit and temperature, respectively which is what we are assessing here). Overall, our baseline FM measurements captured the part of the year where the water balance was negative (when potential evapotranspiration is larger than precipitation, MaySeptember, Fig. 1). The year of measurements (2016) followed a trend in precipitation similar to the longterm average, albeit with a more pronounced summer drought, which allowed for testing under a wider gradient of water scarcity than would usually occur (Fig. 1).

\subsection{Statistical analyses}

Statistical analyses were performed within the R software ( $\mathrm{R}$ Core Team 2016). We estimated whether there was any significant effect of thinning on FM (FM) by the linear mixed model:

$$
\begin{aligned}
\mathrm{FM}_{i j k l}= & B_{i}+T_{j}+(T B)_{i j}+S_{k}+(S T)_{j k}+(S T B)_{i j k} \\
& +\varepsilon_{i j k l}
\end{aligned}
$$

where $B, T$, and $S$ refer to the fixed effects of block, thinning, and sampling day error, respectively, and $T B, S T B$, and $\varepsilon$ are the random effects including the residual error term. Because thinning varied in intensity with plots (Table 1), we additionally calculated $\Delta \mathrm{FM}$, the average difference in FM between unthinned and thinned plots, and regressed it against the basal area $(G)$ and the density $(N)$ removed in the nine pairs of plots. Additionally, because of the differences in $G$ and $N$ across plots before experiment inception, we additionally sought to correlate average FM with $G$ and with $N$ in the 18 plots.

We further analyzed differences across thinning treatments in structural crown components (pCBD, $g$, and SLA) with the model:

$Y_{i j}=T_{j}+\varepsilon_{i j}$

where $Y$ stands for pCBD, $g$, or SLA and $T$ is defined as above, and $\varepsilon$ are random effects including the residual error term. As for FM, we calculated $\triangle \mathrm{pCBD}$ as the difference in pCBD between unthinned and thinned plots and regressed it against $G$ and $N$ removed in the nine pairs of plots. Also, to test for the effects of differences in basal area and stand density, we regressed pCBD against $G$ and $N$ over the 18 plots. We assessed that normality assumption was met during analyses.

Finally, to test for relationships between FWI and components with FM across fuel types, we conducted linear regression analyses between the FMs in each fuel type and each of the FWI components separately for each dataset (e.g., unthinned stands, thinned stands, and baseline measurements). 

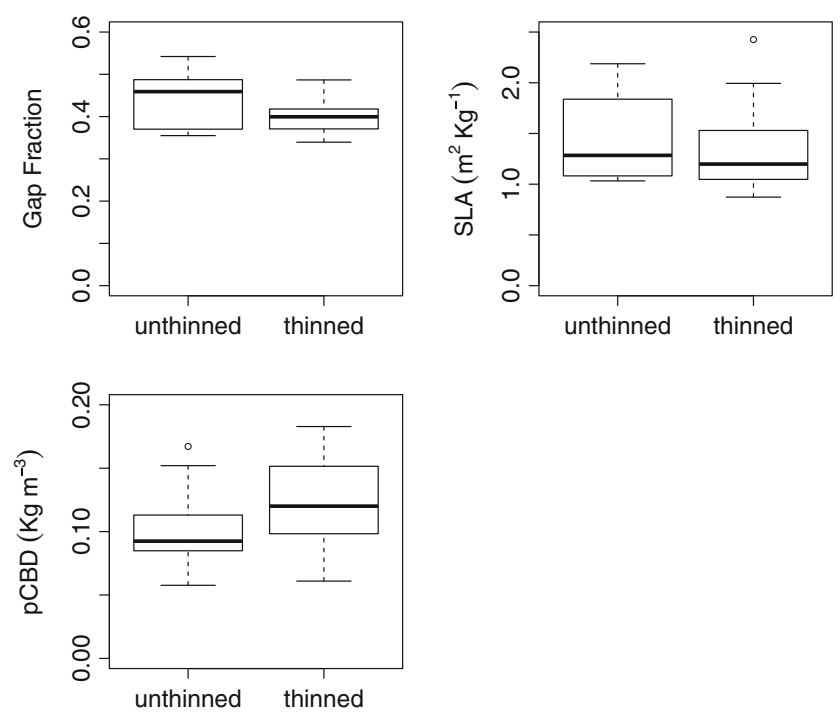

Fig. 2 Box plot on changes in gap fraction, specific leaf area (SLA), and a proxy for crown bulk density (pCBD) as a function of whether the stand has or not undergone thinning. Gap fraction has relative units

\section{Results}

There was no effect of thinning or stand structure on pCBD. We did not observe any difference in gap fraction $(P=0.196)$, SLA $(P=0.81)$, or pCBD $(P=0.33)$ between thinned and unthinned stands (Fig. 2), and there was no significant correlation between $\triangle \mathrm{pCBD}$ and $\% G$ or $\% N$ removed (Fig. 3c, d). Additionally, there was no significant correlation $(P>0.05)$ between pCBD and $G$ and $N$ (Fig. 3a, b).

Thinning had no significant impact on crown FM, and the interaction between thinning and sampling day was not significant (Fig. 4, Table 1). Given such lack of effect for thinning, we did not observe any significant correlation between $\triangle \mathrm{FM}$ and $\% G$ or $\% N$ removed (Fig. $5 \mathrm{c}, \mathrm{d}$ ). There was also no significant relationship $(P>0.05)$ between average FM and $G$ and $N$ (Fig. 5a, b). The baseline measurements provided additional (albeit qualitative) support for a lack of temporal difference in crown FM during a more extended period of the year (Fig. A1).

There was no temporal difference in FM in crown, surface, or suspended fuels (Fig. 4, Table 2). There was only significant temporal variation in the FM of the shrubs, which showed a significant interaction with thinning, such that FM was higher in unthinned (than in thinned) stands at the beginning of the season, but lower towards the middle and the end of the season (Fig. 4, Table 2). Despite the general lack of temporal variability in FM, FWI and some of its components showed marked temporal variability. Drought Code and Duff Moisture Code increased markedly throughout the sampling period (Fig. 6), which led to marked increases in Buildup Index. The continuous increase in Drought Code, Duff Moisture Code, and Buildup Index was only momentarily counteracted by intermittent rain pulses (Fig. 6). Only Fine Fuel Moisture
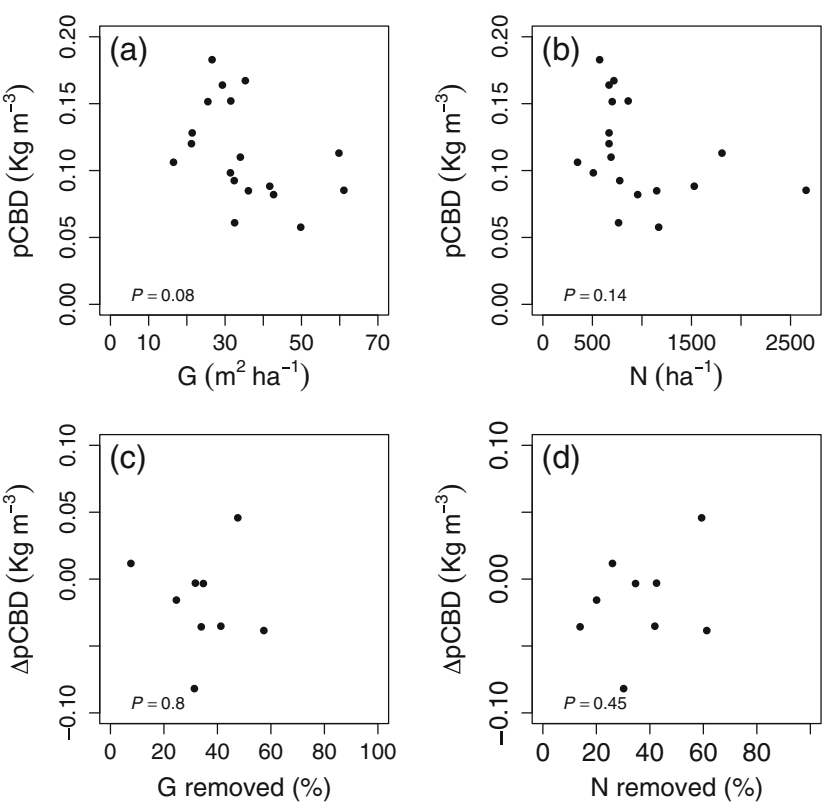

Fig. 3 No effects of stand structure on crown bulk density. a, b Relationships between the proxy for crown bulk density (pCBD) and basal area $(G)$ and density $(N)$ in the 18 plots, respectively. The difference in $\mathrm{pCBD}(\triangle \mathrm{pCBD})$ for each of the nine pairs of thinnedunthinned plots, as a function of the $\%$ removed $G$ and $N$ is shown in $\mathbf{c}$, d, respectively. The $P$ value represents the value of least-squares fitting

Code showed an overall lack of temporal variability. With the exception of rainy periods, Fine Fuel Moisture Code was high and stable through the fire season (Fig. 6), which matched the pattern previously documented for dead FM (Fig. 4). As a consequence of this pattern of temporal variation (and of Initial Spread Index, not shown), FWI varied by $40 \%$ over the sampling season, from 39.3 at the beginning to 65.0 towards the end (except for briefly after rains, when FWI dropped to 0). However, such a marked increase in FWI (Fig. 6) was not mirrored by a similar increase in FM (Fig. 4, Table 2).

We regressed FM across all fuel types against all FWI components for further analyses on the suitability of FWI. This analysis formally corroborated that live FM was not effectively tracked by FWI, Drought Code, or any other components of FWI: regressions were either nonsignificant or with very limited predictive power $\left(R^{2}<0.3\right.$, Table 3$)$. However, there were some significant regressions with high predictive power $\left(R^{2}>0.5\right.$, Table 3$)$ for some of the dead fuel components (especially for surface $10 \mathrm{~h}$ and suspended $10 \mathrm{~h}$, Table 3).

\section{Discussion}

Here, we examine the effects of thinning on some aspects related to crown fire risk in $P$. pinaster forest stands, based on the availability of fuel and on its canopy structure, 7 years 


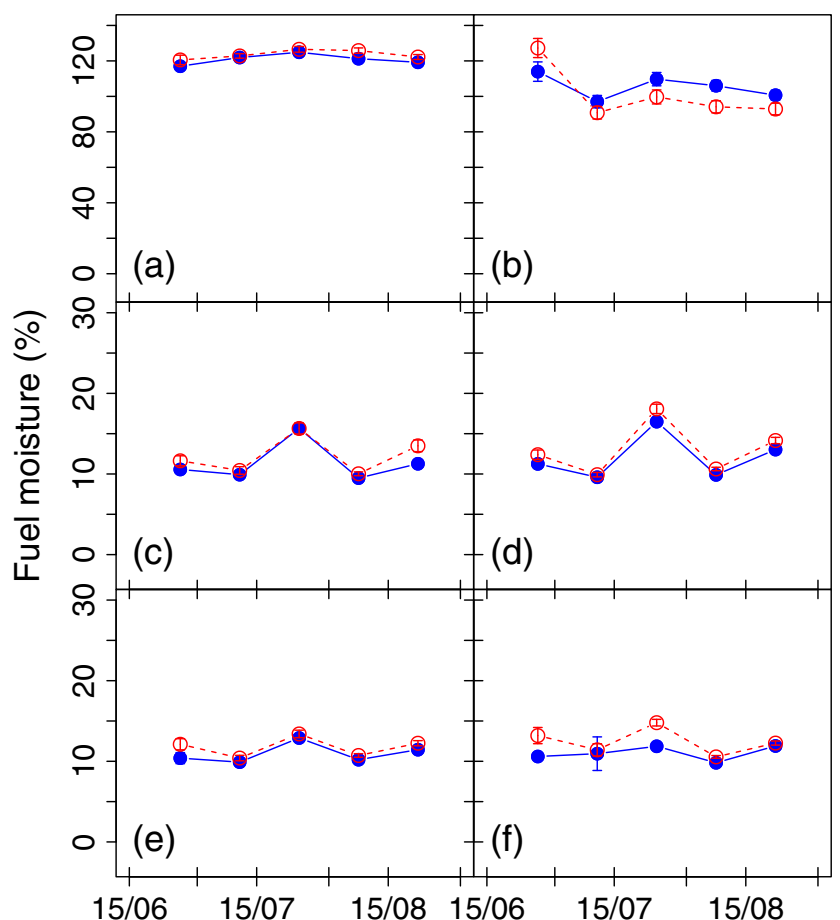

Fig. 4 Time series of fuel moisture in a crown, b shrub, c surface $1 \mathrm{~h}, \mathbf{d}$ surface $10 \mathrm{~h}$, e suspended $1 \mathrm{~h}$, and $\mathbf{f}$ suspended 10-h fuel types in thinned (blue) and not thinned (red) Pinus pinaster plantations. Each value represents the mean of nine sites for live fuel and of five sites for dead fuel. Error bars indicate standard errors, but they may remain hidden due to their small size. $Y$-scale axis differs between live and dead fuel plots

after the thinning was performed. We do not observe any difference in $\mathrm{pCBD}$ or FM with thinning across different types of live and dead fuels, indicating no medium-term effects of silvicultural treatments and of stand structure over these fire risk parameters. Furthermore, the temporal dynamics of FWI and its components do not reflect temporal changes in live FM. Overall, these results have important implications for the management of forest fire risk in Mediterranean pinewoods.

CBD analyses indicate no structural changes in the capacity to carry fires through the crown (i.e., same rate of spread, cf. van Wagner 1977), since differences between thinned and unthinned plots were not significant. This is likely due to a rapid colonization of the airspace by the remaining canopy of the uncut trees. Basal area removed ranged from 8 to $57 \%$ (or from 3 to $34 \mathrm{~m}^{2} \mathrm{ha}^{-1}$ ). Even towards the high end of this range in basal area reductions, we found no effect 7 years after thinning (Fig. 2c, d). It could be argued that any potential effects of thinning could be masked by the high natural variability in basal area $(G)$ and density $(N)$ before experimental inception. However, our results indicate that canopy closure at these stands in the 7 years after thinning precludes any effects of $G$ or $N$ regardless of whether pCBD is compared against variability in $G$ and $N$ (Fig. 2a, b) or if $\triangle$ pCBD is compared against the thinning-induced change in $G$ and $N$ (Fig. 2c, d)
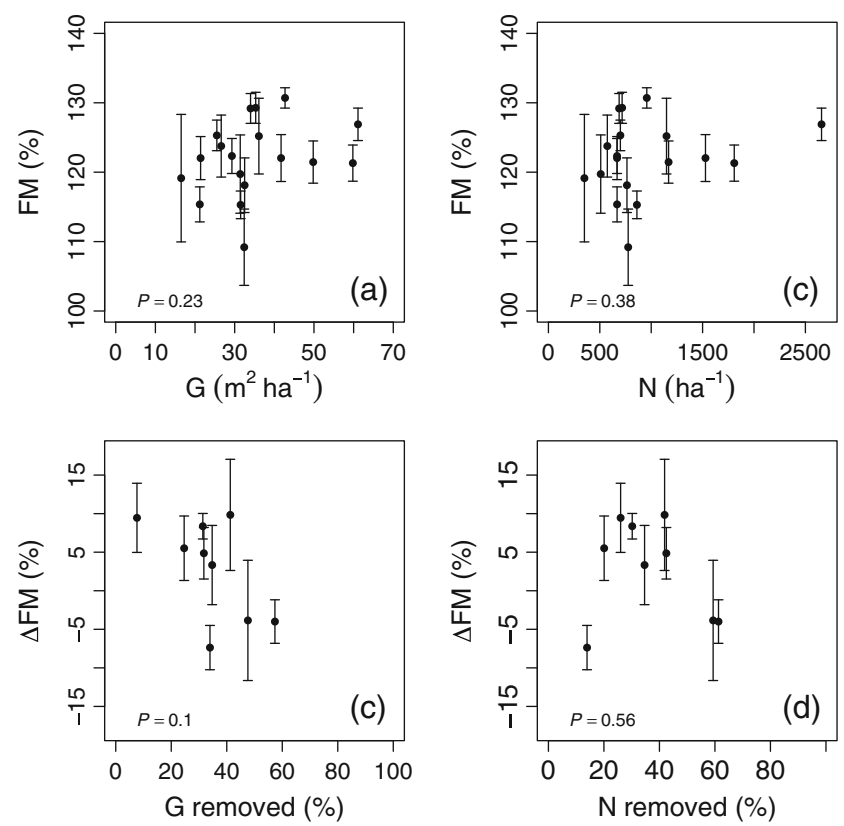

Fig. 5 Stand structure does not affect fuel moisture. Relationship between average fuel moisture (FM) and basal area (a) and stand density (b) for each of the 18 plots and difference in crown fuel moisture $(\triangle \mathrm{FM})$ between thinned and not thinned stands (nine pairs of plots) as a function of the basal area $(G)$ and density $(N)$ removed in relative (c, d) terms. The $P$ value represents the value of least-squares fitting. Error bars indicate standard errors

These results contrast with previous studies on mediumterm effects of thinning on CBD. Jiménez et al. (2016) found that CBD was significantly lower 3 and 5 years after thinning in $P$. pinaster stands of northern central Spain. While $N$ after thinning in that experiment $\left(700-300\right.$ trees $\left.\mathrm{ha}^{-1}\right)$ was similar to those reported here (Table 1), $G$ was much lower (5.7$\left.3.3 \mathrm{~m}^{2} \mathrm{ha}^{-1}\right)$ and initial tree density in that experiment $\left(\sim 4600-4800\right.$ trees $\left.\mathrm{ha}^{-1}\right)$, which examined a stand naturally established after a fire, was much higher than here (Table 1). The stand was also younger (46 years old), and the high tree density in Jiménez et al. (2016) would have imposed a much higher competitive stress prethinning, partly explaining why a longer legacy of the thinning treatment would be expected at that site. We note that thinning could have affected other factors of understory vegetation of relevance for behavior that we did not measure. For instance, some studies have observed differences in understory fuel parameters 10 and 13 years after prescribed burning (Fernandes et al. 2004; Fernandes 2009), and such understory composition is of paramount importance to fully understand potential fire behavior (Madrigal et al. 2016). Our goal, however, was to understand changes in the $\mathrm{CBD}$ and FM as key parameters that determine the potential for crown fire spread, once the flame has reached the crown (van Wagner 1977; Alexander 1988; van Wagner 1993).

The lack of an effect over CBD, $g$, or SLA partly explains why FM also did not differ between thinned and unthinned stands, further emphasizing the transient nature of any effects 
Table 2 Results of LMMs testing the effects of block, sampling day, thinning treatment, and the interaction of the latter two on the different types of existing fuel

\begin{tabular}{|c|c|c|c|c|c|c|c|c|c|c|c|c|c|c|c|c|c|c|}
\hline \multirow[t]{2}{*}{ Fixed factors } & \multicolumn{3}{|c|}{ Crown } & \multicolumn{3}{|c|}{ Shrub } & \multicolumn{3}{|c|}{ Surface $1 \mathrm{~h}$} & \multicolumn{3}{|c|}{ Surface $10 \mathrm{~h}$} & \multicolumn{3}{|c|}{ Suspended $1 \mathrm{~h}$} & \multicolumn{3}{|c|}{ Suspended $10 \mathrm{~h}$} \\
\hline & $d f$ & $\chi^{2}$ & $P$ & $d f$ & $\chi^{2}$ & $P$ & $d f$ & $\chi^{2}$ & $P$ & $d f$ & $\chi^{2}$ & $P$ & $d f$ & $\chi^{2}$ & $P$ & $d f$ & $\chi^{2}$ & $P$ \\
\hline Sampling & 1 & 1.01 & 0.315 & 1 & 5.46 & 0.019 & 1 & 0.35 & 0.552 & 1 & 1.21 & 0.271 & 1 & 0.20 & 0.652 & 1 & 0.27 & 0.605 \\
\hline Thinning & 1 & 1.09 & 0.297 & 1 & 1.99 & 0.158 & 1 & 0.87 & 0.352 & 1 & 1.12 & 0.290 & 1 & 1.18 & 0.276 & 1 & 0.01 & 0.961 \\
\hline Block & 8 & 8.97 & 0.345 & 9 & 54.25 & $<0.0001$ & 4 & 4.88 & 0.300 & 4 & 2.93 & 0.570 & 4 & 5.76 & 0.218 & 4 & 8.34 & 0.008 \\
\hline Sampling $\times$ thinning & 1 & 0.19 & 0.664 & 1 & 4.06 & 0.043 & 1 & 1.77 & 0.674 & 1 & 0.01 & 0.951 & 1 & 0.01 & 0.948 & 1 & 0.62 & 0.432 \\
\hline
\end{tabular}

The model included block crossed to thinning treatment and block crossed to thinning and sampling day as random factors as described in Eq. 3

of forest thinning. The lack of temporal variation in FM is also remarkable. Relationships between live FM and fire occurrence in the literature report rapid increases with area burned when FM drops below 140-100\% (Jurdao and Chuvieco 2012; Nolan et al. 2016) and below 15\% for dead FM (Nolan et al. 2016). Our measured values always fell within this range, indicating that live and dead fuels would be readily available for burning in the area, provided an ignition source and fire weather. The month with highest burned area in Spain is August (MAGRAMA 2012). Our results would indicate that such pattern is not driven by a higher availability of fuel during that period. Instead, we hypothesize that the temporal pattern of burned area in pine forests would be more driven by processes like the number of windy days or the number of ignitions, than by fuel availability. In fact, the temporal pattern of ignitions is highly correlated with burned area
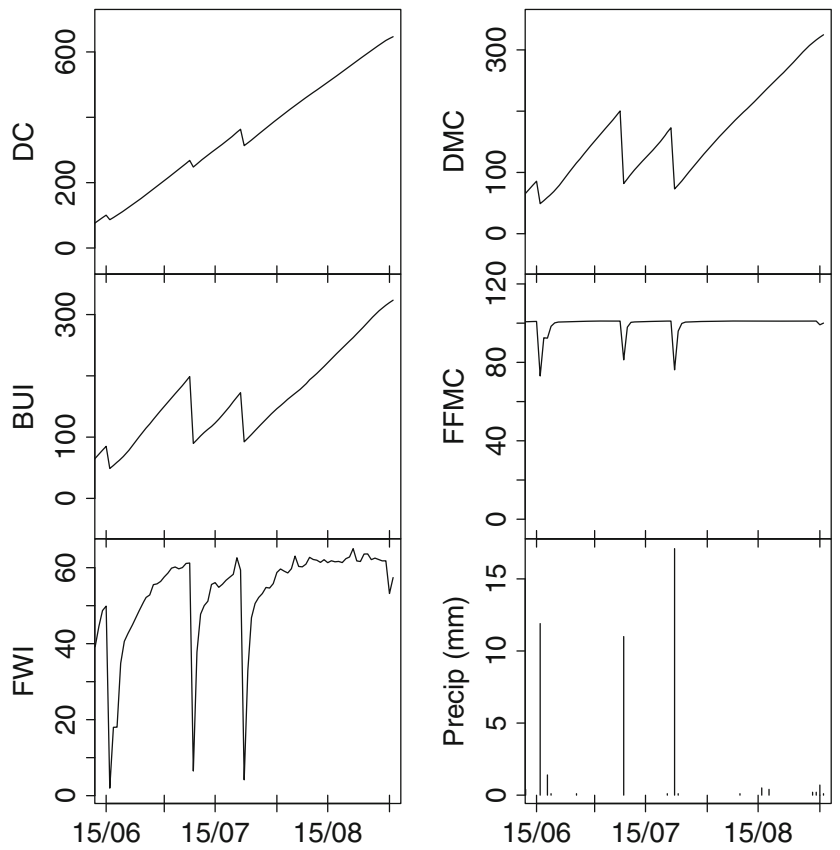

Fig. 6 Time series of some of the components of the Fire Weather index (FWI), namely, the Drought Code (DC), Duff Moisture Code (DMC), Buildup Index (BUI), Fine Fuel Moisture Code (FFMC), and precipitation (precip). FWI and components are unitless
(MAGRAMA 2012). Future studies could address this hypothesis in more depth across different forest types.

Although FM was temporally stable, Drought Code, Duff Moisture Code, Buildup Index, and FWI all predicted an increase in the availability of fuel during the summer. Only the pattern of FFMC, which remained stable through the fire season, was consistent with data on dead FM, and only the moisture in surface $10 \mathrm{~h}$ and in suspended $10 \mathrm{~h}$ fuels was highly correlated $\left(R^{2}>0.5\right)$ with either FWI or some of its components. This is important because FWI is currently in wide use globally. FWI was developed for boreal forests, and although some studies indicate its validity for Mediterranean environments (Viegas et al. 1999; Dimitrakopoulos et al. 2011), our results indicate that its applicability may not be universal.

FWI makes a simple water balance and ignores the physiological behavior of the trees in the stand. The reason why this index showed limited predictive capacity in our study case may be related to the isohydric stomatal regulation of the genus Pinus, as stomata operate to maintain a constant water potential (and hence FM) through the year (Klein 2014). Other physiological mechanisms such as elastic and osmotic adjustments and capacitance, to name a few, may have also decoupled leaf moisture from atmospheric conditions (Ramírez et al. 2012; Blackman et al. 2016). In fact, constant FM is often reported to remain stable in other pine species and, overall, in evergreen trees in the Mediterranean (Viegas et al. 2001). The fact that fuel availability remained constant during the summer period in the study area challenges the wide application of this index for species with isohydric stomatal behavior. Moreover, our results point towards the need for a more mechanistic development of fire risk indices and that more fully encapsulate physiological responses of leaf moisture

Another difference between our results and previous work is that, while we observed FM to remain stable in the shrubby layer, other studies have observed seasonal oscillations in FM at least in some shrub species (Viegas et al. 2001; Castro et al. 2003; Dimitrakopoulos and Bemmerzouk 2003; Pellizzaro et al. 2007). These differences may be explained by the fact that FM often varies in a species-specific manner, and while FM in some species may be reflected by FWI variations, 
Table 3 Results of least squares fitting fuel moisture for different types of fuel against FWI and its components

\begin{tabular}{|c|c|c|c|c|c|c|}
\hline Fuel & FWI & $\mathrm{DMC}$ & DC & FFMC & ISI & BUI \\
\hline \multicolumn{7}{|l|}{ Unthinned } \\
\hline Crown & NS & NS & NS & NS & NS & NS \\
\hline Shrub & NS & 0.0142 & $0.080 * * *$ & NS & $0.028 *$ & 0.017 \\
\hline Surface $1 \mathrm{~h}$ & NS & NS & NS & $0.049^{*}$ & $0.070 * *$ & NS \\
\hline Surface $10 \mathrm{~h}$ & NS & NS & NS & $0.077 * *$ & $0.081 * *$ & NS \\
\hline Suspended $1 \mathrm{~h}$ & NS & NS & NS & NS & NS & NS \\
\hline Suspended $10 \mathrm{~h}$ & 0.069 & $0.046^{*}$ & NS & $0.099 * *$ & $0.080 * *$ & 0.032 \\
\hline \multicolumn{7}{|l|}{ Thinned } \\
\hline Crown & 0.017 & 0.016 & NS & $0.028^{*}$ & $0.025^{*}$ & NS \\
\hline Shrub & NS & NS & NS & NS & NS & NS \\
\hline Surface $1 \mathrm{~h}$ & $0.109 * * *$ & $0.068 * *$ & NS & $0.205 * * *$ & $0.179 * * *$ & $0.039^{*}$ \\
\hline Surface $10 \mathrm{~h}$ & $0.036^{*}$ & NS & NS & $0.116^{* * *}$ & $0.125 * * *$ & NS \\
\hline Suspended $1 \mathrm{~h}$ & NS & NS & NS & $0.036^{*}$ & $0.041 *$ & NS \\
\hline Suspended $10 \mathrm{~h}$ & NS & NS & NS & NS & NS & NS \\
\hline \multicolumn{7}{|l|}{ Baseline } \\
\hline Crown & NS & $0.259 * *$ & $0.227 * *$ & NS & NS & 0.260 ** \\
\hline Shrub & NS & $0.127^{*}$ & $0.099^{*}$ & NS & NS & $0.126^{*}$ \\
\hline Surface $1 \mathrm{~h}$ & $0.166^{* *}$ & NS & NS & NS & $0.267 * * *$ & NS \\
\hline Surface $10 \mathrm{~h}$ & $0.600 * * *$ & $0.162 *$ & $0.138^{*}$ & $0.27 * *$ & $0.731 * * *$ & $0.169^{*}$ \\
\hline Suspended $1 \mathrm{~h}$ & NS & $0.270 * *$ & $0.215^{* *}$ & NS & NS & $0.266^{* *}$ \\
\hline Suspended $10 \mathrm{~h}$ & $0.247 * *$ & NS & NS & $0.27 * *$ & $0.476 * * *$ & NS \\
\hline
\end{tabular}

The values given are the $R^{2}$ when significant (or NS elsewhere), and significance levels : *, **, and *** indicate, respectively, $P<0.01, P<0.05, P<0.01$, and $P<0.0001$. FWI, DMC, DC, FFMC, ISI, and BUI indicate Fire Weather Index, Duff Moisture Code, Drought Code, Fine Fuel Moisture Code, Initial Spread Index, and Buildup Index, respectively. Analyses were performed separately for data from the unthinned stands, from the thinned stands and from the baseline measurements different FM patterns in each species may have canceled in this joint examination of FM across the shrub stratum.

We note that fire risk is not only dependent on FM. Fire risk also depends on the interplay with fuel load, which remains reasonably stable through a growing season, and also on ignitions and fire weather (e.g., windy days). Since dead and live fuels were available throughout the summer, it is tempting to hypothesize that the meteorological aspect of fire risk indices in Mediterranean pine forests during the dry summer could, perhaps, be simplified to just taking into account wind speed and other parameters that may enhance fire spread. Nonetheless, further research needs also include modeling exercises of two- and three-dimensional fire spread across different stand structures (Pimont et al. 2016).

One of the major knowledge gaps in forest behavior modeling lies in predicting when a surface fire will become a crown fire. We are currently using a heuristic approach, based upon the interaction between understory composition and structure with canopy height and density, but we are lacking a mechanistic understanding of fire propagation to and through the canopy (Alexander and Cruz 2011; Scott et al. 2014), although important progress has been made in recent years (Finney et al. 2015; Pimont et al. 2016). Future research efforts should be directed towards addressing mechanistically the transition between surface fire, local torching, and active or independent crown fires. Such mechanistic understanding will be crucial for designing the most effective strategy for shrub clearing and tree thinning that will diminish fire intensity and provide an opportunity for an effective attack. Moreover, this research needs to be encompassed at multiple scales, as any effective forest fire prevention plan needs to take into account landscape and regional perspectives (Moreira et al. 2011). We therefore need a stronger coordination between detailed, plot-level studies such as this one, with physical-based models and also with studies considering broader spatial scales.

Our results serve to point towards another important research gap on the potential changes in fire risk in Mediterranean pine forests under climate change. We have shown how FM does not change seasonally regardless of meteorological conditions. The increase in temperatures and water scarcity predicted for the Mediterranean Basin under climate change would thus not lead to lower FM in isohydric pine species. However, it has been documented how increasing water 
scarcity in the area has led to widespread defoliation (Carnicer et al. 2011), and if continued, it could lead to significant growth reductions and mortality (Allen et al. 2010; Voltas et al. 2013; Shestakova et al. 2016). Therefore, if FM does not change with global warming, but if defoliation and mortality do increase, we could encounter how the flammability of pine forests diminishes under climate change. Such potential decline in summer flammability could be counteracted by a lengthening of the fire season, amongst other processes, and leads to complex dynamics. Understanding how plant physiology mediates in expected responses to fire under climate change remains as an important knowledge gap from which to move on.

\section{Conclusions}

While it is commonly assumed that thinning reduces CBD for 15-20 years in pine forests, we observed no midterm differences in CBD between thinned and unthinned stands. While FM is often thought to decline as water scarcity increases during Mediterranean summers, we observed homeostasis in foliage moisture, as a likely result of the isohydric behavior of stomata in P. pinaster. Finally, we observed that FWI did not mirror the dynamics of canopy and shrub FM, limiting its predictive capacity on fuel availability for these forests. Further studies to confirm these findings in more species and sites are necessary, but overall, they indicate the need to revise commonly held assumptions on forest fire management.

\begin{abstract}
Acknowledgements This study was made possible thanks to the collaboration of A Vallvey and the staff from the Natural Park of Poblet, P Sopeña, and the technical staff from MedForLab. We remain indebted to two anonymous reviewers and the editors for their help to improve our manuscript.
\end{abstract}

\section{Compliance with ethical standards}

Funding This study is funded by the Spanish Government (RYC-201210970, AGL2015-69151-R, AGL2015-68274-C3-3-R).

\section{References}

Agee JK, Skinner CN (2005) Basic principles of forest fuel reduction treatments. For Ecol Manag 211:83-96

Alexander ME (1988) Help with making crown fire assessments. In: Fischer WC, Arno SF (eds) Protecting people and homes from wildfire in the Interior West: Proceedings of the symposium and workshop. US Department of Agriculture, Forest Service, Intermountain Research Station, Ogden

Alexander ME, Cruz MG (2011) Crown fire dynamics in conifer forests. In: Werth PA, Potter BE, Clements CB et al. (Eds.), Synthesis of knowledge of extreme fire behavior: volume I for fire managers. Gen. Tech. Rep. PNW-GTR-854., U.S. Department of Agriculture,
Forest Service, Paci c Northwest Research Station, Portland, OR, pp. 107-143

Alfaro-Sánchez R, Camarero J et al (2016) Post-fire Aleppo pine growth, $\mathrm{C}$ and $\mathrm{N}$ isotope composition depend on site dryness. Trees 30:581595

Allen CD, Macalady AK et al (2010) A global overview of drought and heat-induced tree mortality reveals emerging climate change risks for forests. For Ecol Manag 259:660-684

Alvarez A, Gracia M et al (2012) Patterns of fuel types and crown fire potential in Pinus halepensis forests in the Western Mediterranean Basin. For Ecol Manag 270:282-290

Bedia J, Herrera S et al (2015) Global patterns in the sensitivity of burned area to fire-weather: implications for climate change. Agric For Meteorol 214-215:369-379

Blackman CJ, Pfautsch S et al (2016) Toward an index of desiccation time to tree mortality under drought. Plant Cell Environ 39:23422345

Boer MM, Price OF et al (2015) Wildfires: weigh policy effectiveness. Science 350:920

Bonet JA, de Miguel S et al (2012) Immediate effect of thinning on the yield of Lactarius group deliciosus in Pinus pinaster forests in Northeastern Spain. For Ecol Manage 265:211-217

Bradstock RA (2010) A biogeographic model of fire regimes in Australia: current and future implications. Glob Ecol Biogeogr 19:145-158

Carnicer J, Coll M et al (2011) Widespread crown condition decline, food web disruption, and amplified tree mortality with increased climate change-type drought. Proc Nat Acad Sci 108:1474-1478

Castro F, Tudela A et al (2003) Modeling moisture content in shrubs to predict fire risk in Catalonia (Spain). Agric For Meteorol 116:49-59

Dimitrakopoulos A, Bemmerzouk AM (2003) Predicting live herbaceous moisture content from a seasonal drought index. Int J Biometeorol 47:73-79

Dimitrakopoulos AP, Bemmerzouk AM et al (2011) Evaluation of the Canadian fire weather index system in an eastern Mediterranean environment. Meteorol Appl 18:83-93

Duursma R (2013) canopyphoto: analyze canopy photos for gap fraction. $\mathrm{R}$ package version $0.0-3$

Fernandes PM (2009) Examining fuel treatment longevity through experimental and simulated surface fire behaviour: a maritime pine case study. Can J For Res 39:2529-2535

Fernandes PAM, Loureiro CA et al (2004) Fire behaviour and severity in a maritime pine stand under differing fuel conditions. Ann For Sci 61:537-544

Fernandes PM, Davies GM et al (2013) Prescribed burning in southern Europe: developing fire management in a dynamic landscape. Front Ecol Environ 11:e4-e14

Finney MA, Cohen JD et al (2015) Role of buoyant flame dynamics in wildfire spread. Proc Nat Acad Sci 112:9833-9838

Gil L, Gordo J et al (1990) Pinus pinaster Aiton en el paisaje vegetal de la Península Ibérica. Ecología 1:469-495

Jiménez E, Vega-Nieva D et al (2016) Midterm fuel structure recovery and potential fire behaviour in a Pinus pinaster Ait. forest in northern central Spain after thinning and mastication. Eur J For Res 135: 675-686

Jurdao S, Chuvieco E (2012) Modelling fire ignition probability from satellite estimates of live fuel moisture content. Fire Ecol 7:77-97

Keane RE, Reinhardt ED et al (2005) Estimating forest canopy bulk density using six indirect methods. Can J For Res 35:724-739

Klein T (2014) The variability of stomatal sensitivity to leaf water potential across tree species indicates a continuum between isohydric and anisohydric behaviours. Funct Ecol 28:1313-1320

Kreye JK, Kobziar LN et al (2014) Immediate and short-term response of understory fuels following mechanical mastication in a pine flatwoods site of Florida, USA. For Ecol Manag 313:340-354

Madrigal J, Fernández-Migueláñez I et al (2016) Does forest biomass harvesting for energy reduce fire hazard in the Mediterranean basin? 
A case study in the Caroig Massif (Eastern Spain). Eur J For Res 136:13-26

MAGRAMA (2012) Los incendios forestales en España. Decenio 20012010., Madrid

McIver JD, Stephens SL et al (2013) Ecological effects of alternative fuelreduction treatments: highlights of the National Fire and Fire Surrogate study (FFS). Int J Wildland Fire 22:63-82

Moreira F, Viedma O et al (2011) Landscape-wildfire interactions in southern Europe: implications for landscape management. J Environ Manage 92:2389-2402

Moreno JM, Vallejo VR et al (2013) Current fire regimes, impacts and the likely changes - VI: Euro Mediterranean. In: Goldammer JG (ed) Vegetation fires and global change. Kessel Publishing House, Remagen-Oberwinter, pp 115-132

Moritz MA, Batllori E et al (2014) Learning to coexist with wildfire. Nature 515:58-66

Nolan RH, Boer MM et al (2016) Large scale, dynamic transformations in fuel moisture drive wildfire activity across south-eastern Australia. Geophys Res Lett 43:4229-4238

North MP, Stephens SL et al (2015) Reform forest fire management. Science 349:1280-1281

Pellizzaro G, Duce P et al (2007) Seasonal variations of live moisture content and ignitability in shrubs of the Mediterranean Basin. Int J Wildland Fire 16:633-641

Pimont F, Parsons R et al (2016) Modeling fuels and fire effects in 3D: model description and applications. Environ Model Softw 80:225244

Piñol J, Castellnou M et al (2007) Conditioning uncertainty in ecological models: assessing the impact of fire management strategies. Ecol Model 207:34-44

Potts JB, Marino E et al (2010) Chaparral shrub recovery after fuel reduction: a comparison of prescribed fire and mastication techniques. Plant Ecol 210:303-315

Pretzsch H (2009) Forest dynamics, growth and yield-from measurement to model. Springer-Verlag, Berlin $664 \mathrm{p}$

R Core Team (2016) R: a language and environment for statistical computing. R Foundation for Statistical Computing, Vienna, Austria. http://www.R-project.org/

Ramírez DA, Parra A et al (2012) Differences in morpho-physiological leaf traits reflect the response of growth to drought in a seeder but not in a resprouter Mediterranean species. Funct Plant Biol 39:332341

Resco de Dios V (2016) When fire acts like an irrigation: competition release after burning enhances growth. Trees 30:579-580
Resco de Dios V, Fellows AW et al (2015) A semi-mechanistic model for predicting the moisture content of fine litter. Agric For Meteorol 203:64-73

Rothermel RC (1983) How to predict the spread and intensity of forest and range fires. US Department of Agriculture, Forest Service, Intermountain Forest and Range Experiment Station, Ogden

San-Miguel J, Camia A (2009) Forest fires at a glance: facts, figures and trends in the EU. In: Birot Y. (Ed.) Living with wildfires: what science can tell us, European Forest Institute, pp 11-21

Schneider CA, Rasband WS et al (2012) NIH Image to ImageJ: 25 years of image analysis. Nat Methods 9:671-675

Scott AC Bowman DMJS et al. (2014) Fire on earth: an introduction. Wiley-Blackwell

Shestakova TA, Gutiérrez E et al (2016) Forests synchronize their growth in contrasting Eurasian regions in response to climate warming. Proc Nat Acad Sci 113:662-667

Stephens SL, Collins BM et al (2012) Fuel treatment longevity in a Sierra Nevada mixed conifer forest. For Ecol Manag 285:204-212

Vadell E, de Miguel S et al (2016) Large-scale reforestation and afforestation policy in Spain: a historical review of its underlying ecological, socioeconomic and political dynamics. Land Use Policy 55:3748

van Wagner CE (1977) Conditions for the start and spread of a crown fire. Can J For Res 33:23-34

van Wagner CE (1987) Development and structure of the Canadian Forest Fire Weather Index System, Canadian Forestry Service, Ottawa, ON, Technical Report $35 \mathrm{p}$

van Wagner CE (1993) Predictions of crown fire behavior in two stands of jack pine. Can J For Res 23:442-449

Vélez R (2010) La Defensa contra Incendios Forestales: Fundamentos y Experiencias. McGraw Hill, Madrid 841 p

Viegas DX, Bovio G et al (1999) Comparative study of various methods of fire danger evaluation in southern Europe. Int J Wildland Fire 9: 235-246

Viegas DX, Piñol J et al (2001) Estimating live fine fuels moisture content using meteorologically-based indices. Int J Wildland Fire 10:223 240

Voltas J, Camarero JJ et al (2013) A retrospective, dual-isotope approach reveals individual predispositions to winter-drought induced tree dieback in the southernmost distribution limit of Scots pine. Plant Cell Environ 36:1435-1448

Welles JM, Cohen S (1996) Canopy structure measurement by gap fraction analysis using commercial instrumentation. J Exp Bot 47:13351342 